\title{
Strength Developments and Deformation Characteristics of MMA-Modified Vinyl Ester Polymer Concrete
}

\author{
Nan Ji Jin'), Jaeheum Yeon ${ }^{2), *}$ (1), Seung-Ho Min ${ }^{3)}$, and Kyu-Seok Yeon ${ }^{4}$
}

(Received September 3, 2017, Accepted October 26, 2017)

\begin{abstract}
This study investigated the strength developments and deformation characteristics of methyl methacrylate (MMA)modified vinyl ester polymer concrete, with MMA contents and curing temperatures as test variables. To lower the viscosity of the vinyl ester resin applied as a binder, an MMA monomer was added. In this study, the developed 168-h compressive and flexural strengths were 43.8-77.2 and 18.2-21.8 MPa, respectively. Also, these values decreased as MMA contents increased and curing temperatures decreased. The coefficient of thermal expansion ranged from $10.82 \times 10^{-6}$ to $14.23 \times 10^{-6} /{ }^{\circ} \mathrm{C}$, and it decreased as an MMA content increased. The ultimate compressive strain ranged from 0.00391 to 0.00494 , which decreased with an increase in MMA contents and notably decreased with a decrease in curing temperatures. The modulus of elasticity tended to decrease as MMA contents increased and curing temperatures decreased.
\end{abstract}

Keywords: polymer concrete, vinyl ester resin, compressive strength, flexural strength, thermal expansion coefficient, modulus of elasticity.

\section{Introduction}

Concrete-polymer composites are generally one of three classifications, i.e., polymer-modified (or cement) concrete (PCC), polymer concrete (PC), or polymer-impregnated concrete (PIC) (Chandra and Ohama 1994). Both PCC and PC have been in commercial use since the 1950s and PIC has been in use since the 1970s (Mehta and Monteiro 2006). The representative characteristic of polymer concrete is rapid hardening. The hardening time of polymer concrete is much faster than the hardening time of ordinary portland cement concrete. Therefore, by applying polymer concrete, the curing time of cast-in-place applications can be reduced and the productivity of precast construction products can be enhanced. Hence, it is applied for cast-in-place applications and precast construction applications such as building panels, utility boxes, and underground junction boxes. Also, polymer concrete is employed mainly as a patching material to fill

\footnotetext{
${ }^{1)}$ Dongil Engineering Consultants Co., Ltd, Seoul 05800, Republic of Korea.

${ }^{2)}$ Department of Engineering \& Technology, Texas A\&M University-Commerce, Commerce, TX 75429-3011, USA.

*Corresponding Author; E-mail: jyeon81@tamu.edu

${ }^{3)}$ Building Projects Operation Division, GS Engineering \& Construction, Seongnam 13639, Republic of Korea.

${ }^{4)}$ Department of Regional Infrastructure Engineering, Kangwon National University, Chuncheon 24341, Republic of Korea.

Copyright $\odot$ The Author(s) 2018. This article is an open access publication
}

minor damages and to overlay damaged concrete bridge pavement surfaces (Chandra and Ohama 1994; Fowler 1989).

The binder principally used to produce polymer concrete is a thermosetting resin (e.g., unsaturated polyester, epoxy, acrylic, and vinyl ester). Also, apparent differences existed in the physical and mechanical properties depending on the type of binder (Haddad et al. 1983; Hyun and Yeon 2012; Ohama 1973). In addition, studies to improve the properties of these binders have been actively conducted (Hyun and Yeon 2012; Son and Yeon 2012).

In this study, vinyl ester resin was chosen as a binder. Due to its excellent chemical and corrosion resistances coupled with outstanding heat resistance, it is suitable for practical applications, such as in swimming pools, sewer pipes, and solvent storage tanks (Cao and Lee 2003; Cook et al. 1997).

An MMA monomer used in this study as a reforming agent has low viscosity, and thus is effective in lowering the viscosity of generally high viscosity resins. Also, it not only has excellent chemical and corrosion resistances but also high bond strengths (Hyun and Yeon 2012). By taking the advantages of vinyl ester resin and an MMA monomer, it is possible to lower the viscosity of the binder, as well as improve workability and various properties of polymer concrete. However, despite these advantages of MMA monomer-modified vinyl ester resin, there are few existing studies except for research on evaluating the setting shrinkage characteristics of MMA-modified vinyl ester polymer concrete (Choi et al. 2016).

Thus, in this study, polymer concrete using MMA monomer-modified vinyl ester resin is applied as a binder to examine the effects of MMA contents and curing temperatures on compressive strengths, flexural strengths, the 


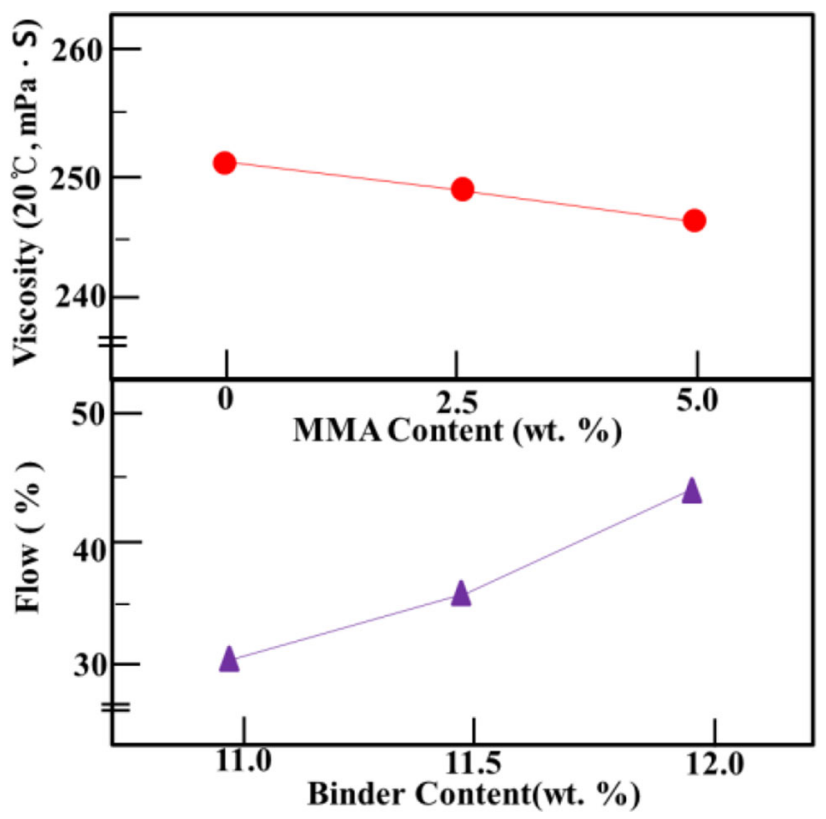

Fig. 1 Flow and viscosity characteristics with respect to binder and MMA contents. coefficient of thermal expansion, and the modulus of elasticity. The ultimate purpose of this study is to examine the strength developments and deformation characteristics at various MMA contents and curing temperatures. Hence, the fundamental material properties determined in this study can be referred to by designers or contractors who have decided to apply vinyl ester polymer concrete in both cast-in-place and precast construction applications.

\section{Materials}

\subsection{Vinyl Ester Resin}

Vinyl ester (VE) resin is an adduct of epoxy resin and an unsaturated carboxylic acid such as acrylic or methacrylic acid (Martin et al. 2000). This vinyl ester resin can be cured at room temperature and its curing time can be easily controlled by the amounts of initiator and promoter. The vinyl ester resin applied as the main binder in this study was a bisphenol A epoxy-based vinyl ester resin, and its properties are listed in Table 1.
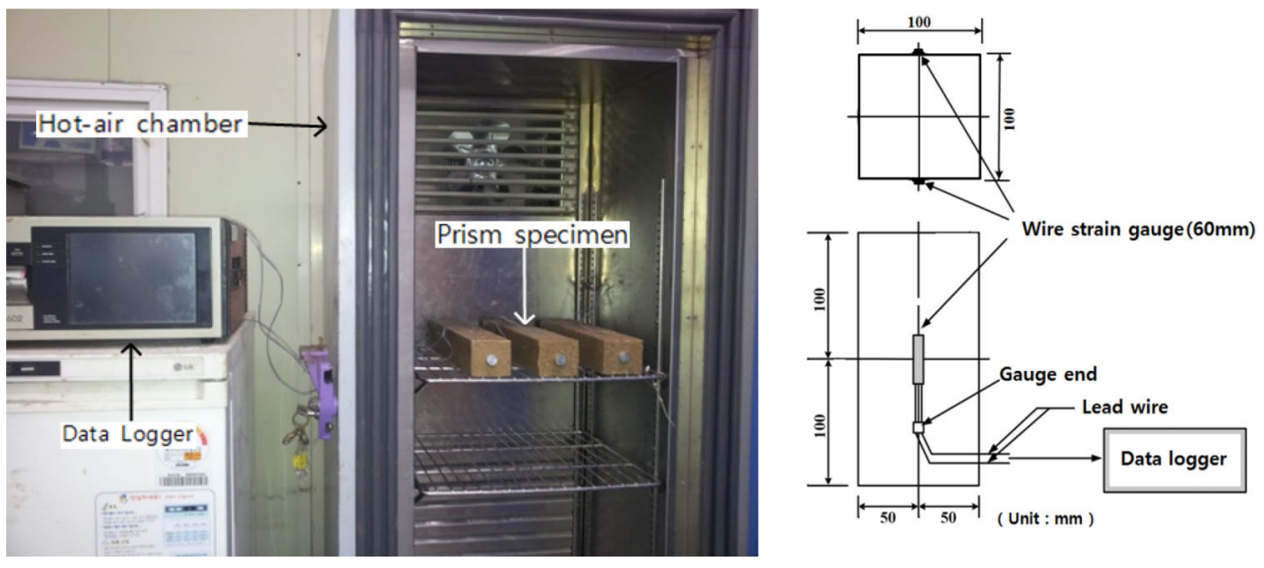

Fig. 2 Test setup for determining thermal expansion.

Table 1 Properties of vinyl ester resin.

\begin{tabular}{c|c|c|c}
\hline Density $\left(25^{\circ} \mathrm{C}\right)$ & Viscosity $\left(20^{\circ} \mathrm{C}, \mathrm{mPa} \cdot \mathrm{s}\right)$ & Vapor density & Styrene content $(\%)$ \\
\hline \hline 1.2 & 250 & 3.6 & 45 \\
\hline
\end{tabular}

Table 2 Properties of MMA monomer.

\begin{tabular}{c|c|c|c}
\hline Density $\left(25^{\circ} \mathrm{C}\right)$ & Viscosity $\left(20^{\circ} \mathrm{C}, \mathrm{mPa} \cdot \mathrm{s}\right)$ & Molecular weight $(\mathrm{g} / \mathrm{mol})$ & Appearance \\
\hline \hline 0.9420 & 0.56 & 100 & Transparent \\
\hline
\end{tabular}

Table 3 Properties of MEKPO.

\begin{tabular}{c|c|c}
\hline Component & Specific gravity $\left(25^{\circ} \mathrm{C}\right)$ & Active oxygen \\
\hline \hline MEKPO 55\% & 1.12 & 10.0 \\
\hline DMP $45 \%$ & & \\
\hline
\end{tabular}

Table 4 Properties of cobalt naphthenate.

\begin{tabular}{c|c|c}
\hline Density $\left(25^{\circ} \mathrm{C}\right)$ & Boiling point $\left({ }^{\circ} \mathrm{C}\right)$ & Appearance \\
\hline \hline 0.95 & 110.6 & Violet liquid \\
\hline \hline
\end{tabular}


Table 5 Physical properties of aggregate.

\begin{tabular}{c|c|c|c|c|c}
\hline Size $(\mathrm{mm})$ & $\begin{array}{c}\text { Apparent specific } \\
\text { gravity }\end{array}$ & Bulk density $\left(\mathrm{kg} / \mathrm{m}^{3}\right)$ & Fineness modulus & Moisture content (\%) & Organic impurities \\
\hline \hline $0.08-8$ & 2.64 & 1648 & 3.09 & $<0.5$ & Nil \\
\hline
\end{tabular}

Table 6 Properties of ground calcium carbonate.

\begin{tabular}{c|c|c|c|c|c}
\hline Specific gravity & Bulk density $(\mathrm{g} / \mathrm{cc})$ & Moisture content (\%) & $\mathrm{pH}$ & Mean grain size $(\mu \mathrm{m})$ & $\begin{array}{c}\text { Retained percentage of } \\
325 \text { mesh sieve }\end{array}$ \\
\hline \hline 2.70 & 0.75 & $\leqq 0.3$ & 8.8 & 13 & 14.3 \\
\hline
\end{tabular}

Table 7 Chemical components of ground calcium carbonate (unit: \%).

\begin{tabular}{c|c|c|c|c|c}
\hline $\mathrm{CaO}$ & $\mathrm{Al}_{2} \mathrm{O}_{3}$ & $\mathrm{Fe}_{2} \mathrm{O}_{3}$ & $\mathrm{SiO}_{2}$ & $\mathrm{MgO}$ & Ignition loss \\
\hline \hline 53.7 & 0.25 & 0.09 & 2.23 & 0.66 & 42.4 \\
\hline
\end{tabular}

Table 8 Binder formulations and mixture proportions of polymer concrete.

\begin{tabular}{c|c|c|c|c|c}
\hline \multirow{2}{*}{ Binder content $(\mathrm{wt} \%)$} & \multicolumn{3}{|c|}{ Binder formulation } & Filler (wt\%) & Fine aggregate (wt\%) \\
\cline { 2 - 6 } & VE:MMA (wt\%) & MEKPO $\left(\mathrm{phr}^{\mathrm{b}}\right)$ & $\begin{array}{c}\text { Cobalt naphthenate } \\
\left(\mathrm{phr}^{\mathrm{b}}\right)\end{array}$ & & \\
\hline \hline $12.0\left(276^{\mathrm{a}}\right)$ & $100\left(276^{\mathrm{a}}\right): 0\left(0^{\mathrm{a}}\right)$ & $2\left(5^{\mathrm{a}}\right)$ & $2\left(5^{\mathrm{a}}\right)$ & $18.00\left(414^{\mathrm{a}}\right)$ & $70.00\left(1610^{\mathrm{a}}\right)$ \\
\hline $11.5\left(265^{\mathrm{a}}\right)$ & $97.5\left(258^{\mathrm{a}}\right): 2.5\left(7^{\mathrm{a}}\right)$ & & & $17.25\left(397^{\mathrm{a}}\right)$ & $71.25\left(1638^{\mathrm{a}}\right)$ \\
\hline $11.0\left(253^{\mathrm{a}}\right)$ & $95.0\left(240^{\mathrm{a}}\right): 5.0\left(13^{\mathrm{a}}\right)$ & & & $16.50\left(380^{\mathrm{a}}\right)$ & $72.50\left(1667^{\mathrm{a}}\right)$ \\
\hline
\end{tabular}

${ }^{a}$ Mass per unitary volume $\left(\mathrm{kg} / \mathrm{cm}^{3}\right)$.

${ }^{\mathrm{b}}$ Parts per hundred parts of resin.
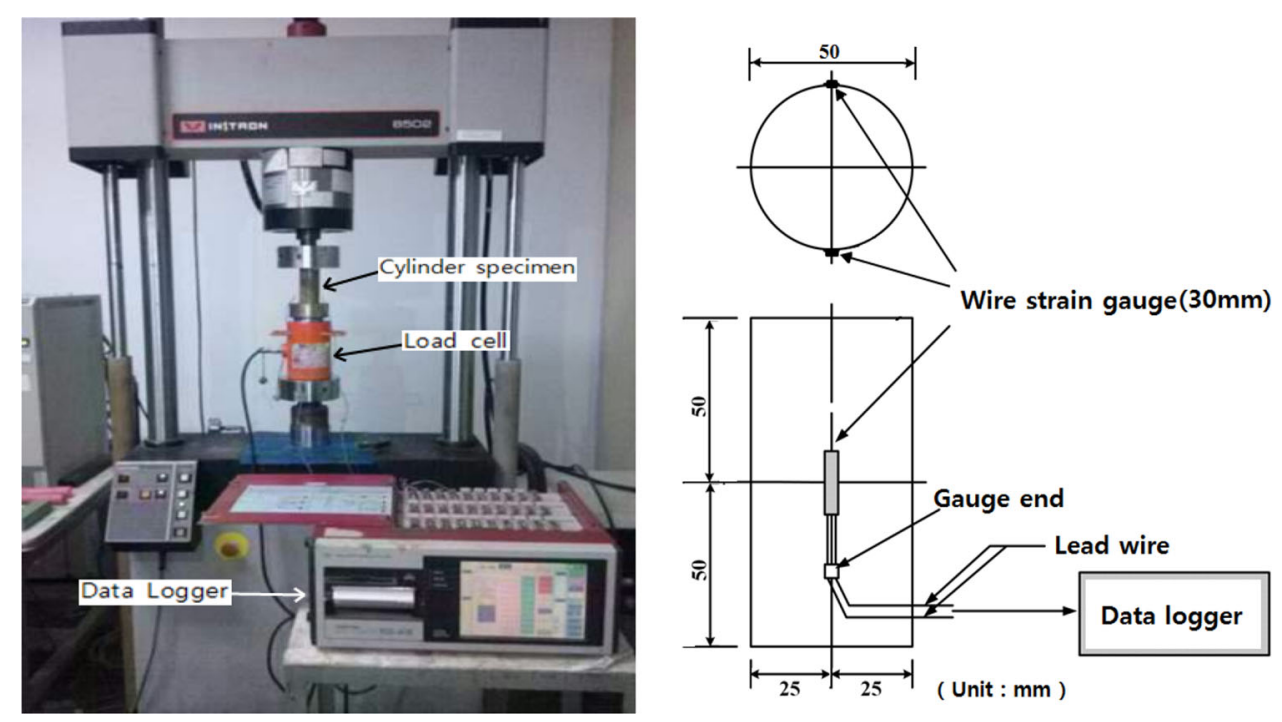

Fig. 3 Test setup for determining the elastic modulus.

\subsection{MMA Monomer}

Methyl methacrylate (MMA) is a colorless liquid, made by producing methacrylic acid through the oxidization of $\mathrm{C} 4$ raffinate-extracted isobutylene in a gaseous state and then esterifying the methacrylic acid with methanol. In general, the characteristics of MMA include excellent transparency, strong weather resistance, and good colorability. MMA was applied as a modifier of vinyl ester resin in this study, the properties of which are shown in Table 2.

\subsection{Initiator}

An initiator and a promoter should be added to harden the vinyl ester resin. A dimethyl phthalate (DMP) solution with $55 \%$ methyl ethyl ketone peroxide (MEKPO) was applied as 


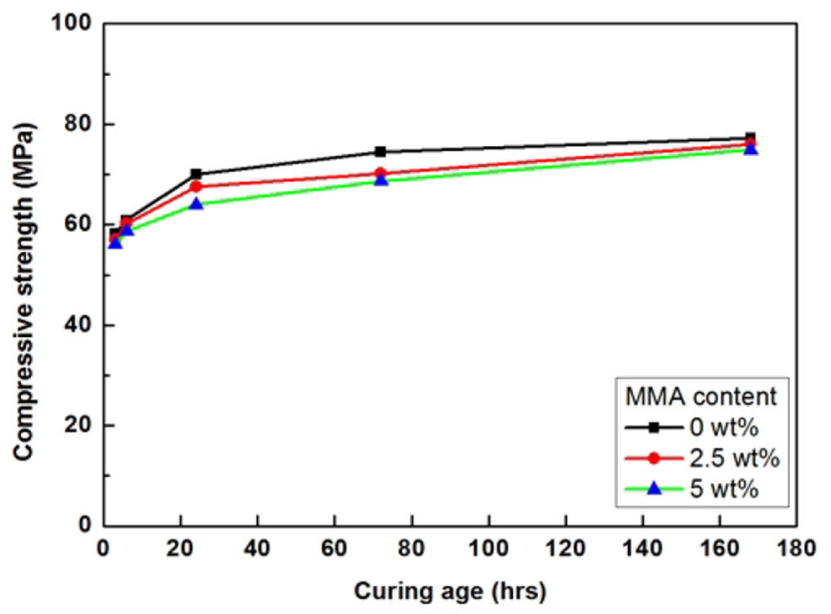

(a)

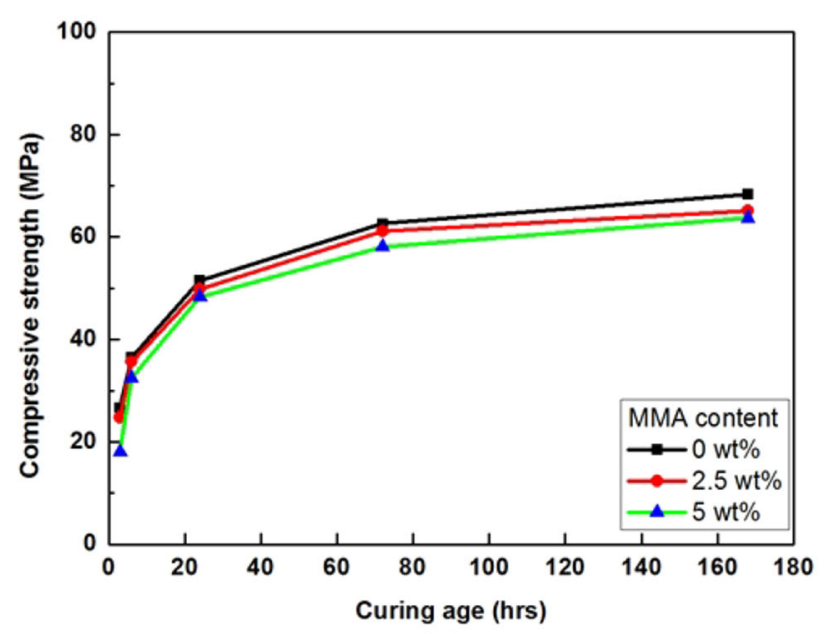

(b)

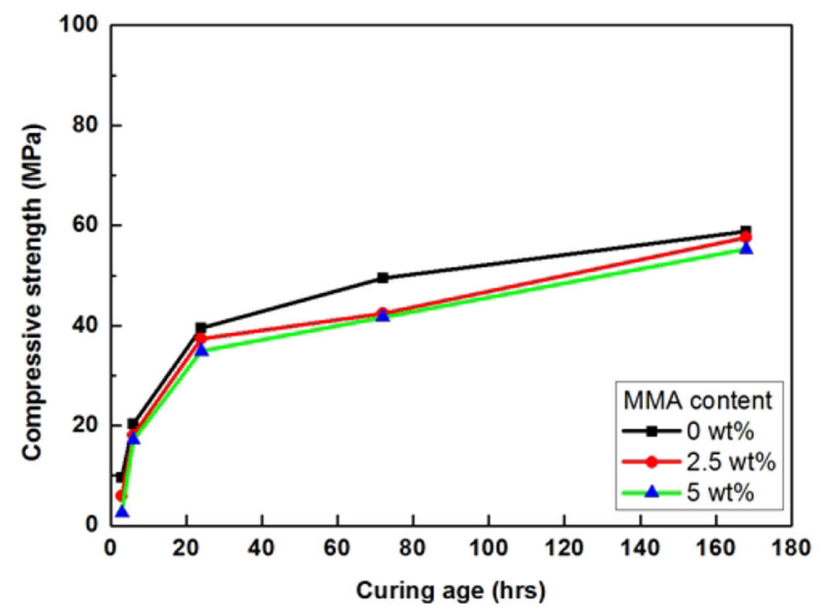

(c)

Fig. 4 Curing age versus compressive strength with MMA content. a $20^{\circ} \mathrm{C}$, b $10^{\circ} \mathrm{C}, \mathbf{c} 0{ }^{\circ} \mathrm{C}$.

an initiator for vinyl ester resin. The properties of the initiator are listed in Table 3.

\subsection{Promoter}

Vinyl ester resin and MMA do not react with each other in a copolymerization state when only an initiator is added. Accordingly, to initiate a quick curing reaction, a promoter is required. In this study, cobalt naphthenate, which enables International Journal of Concrete Structures and Materials

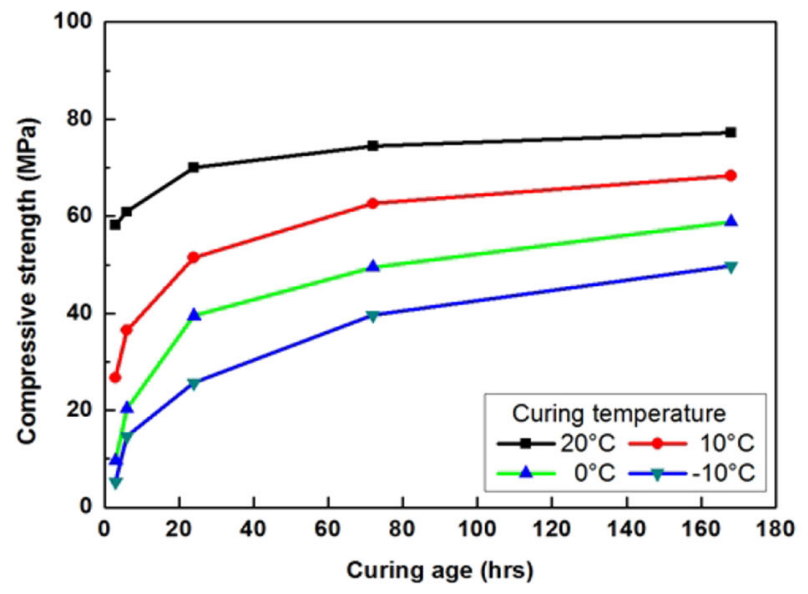

(a)

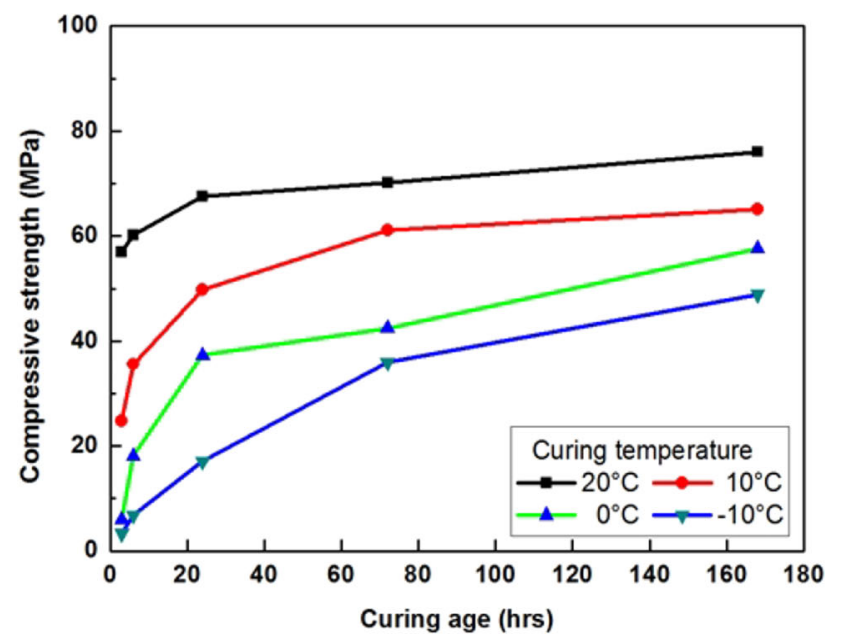

(b)

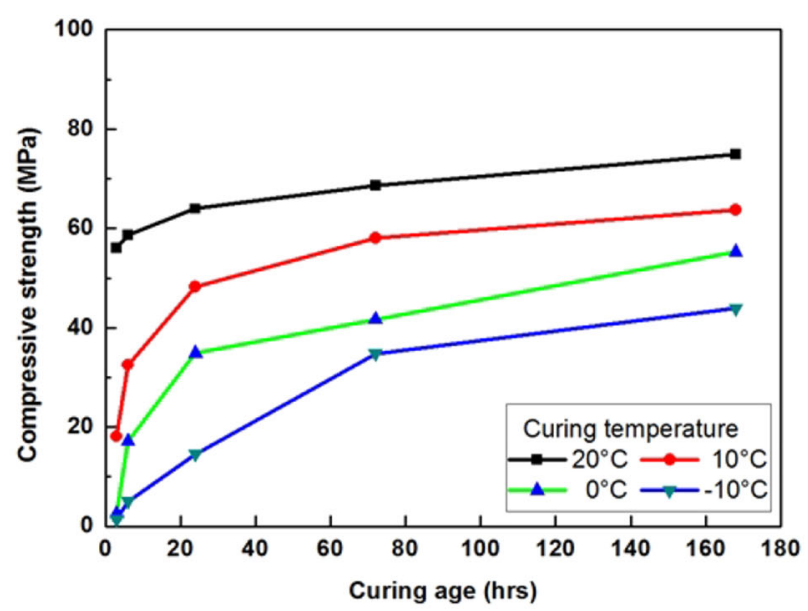

(c)

Fig. 5 Curing age versus compressive strength with curing temperature. a MMA 0 wt $\%$, b MMA $2.5 \mathrm{wt} \%$, and c MMA $5 \mathrm{wt} \%$.

polymerization at both room temperatures and low temperatures, was used as a promoter. The properties of the promoter are presented in Table 4.

\subsection{Aggregate and Filler}

For this study, silica sand was applied as an aggregate. The physical properties of the aggregate used are shown in 


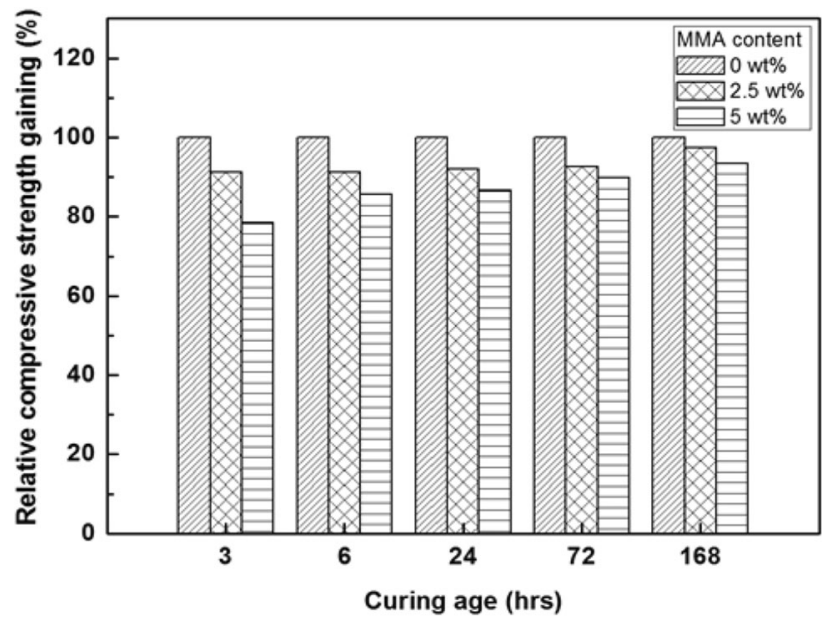

Fig. 6 Relative gain of compressive strength with MMA content.

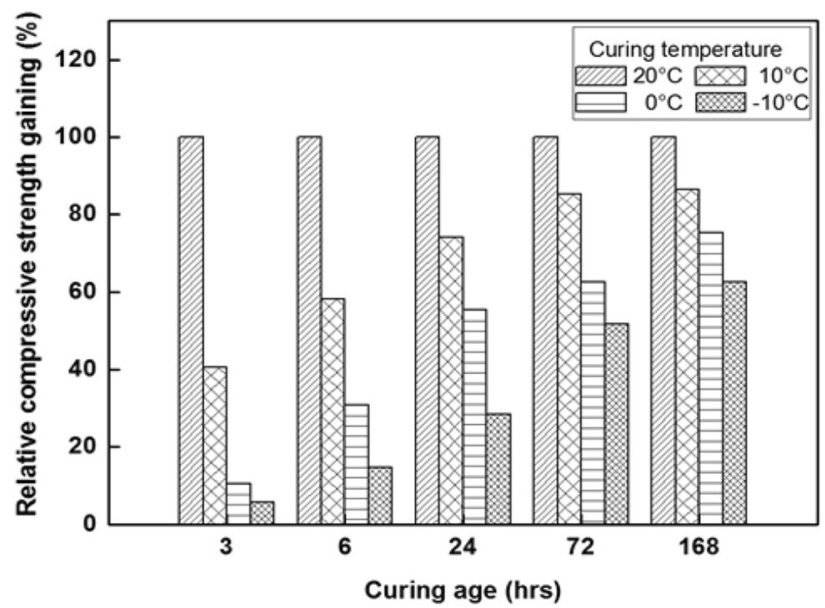

Fig. 7 Relative gain of compressive strength with curing temperature.

Table 5. In addition, this study adopted a ground calcium carbonate powder as a filler because it is inexpensive and easily available. Also, its workability is good because it generally does not absorb the polymer binder. A filler prevents the aggregate from being separated because the state of the polymer binder is changed to a paste when a filler is mixed with the polymer binder. The physical properties and chemical components of the filler used are provided in Tables 6 and 7, respectively.

\section{Methods}

\subsection{Determination of Mixture Proportions}

In this study, optimum mixture proportions were selected based on a series of trial tests on slump loss and strength. The optimum mixture proportions can be achieved when maximizing the amount of aggregate, while minimizing the amount of polymer binder, as long as a certain degree of workability and strength is respectively ensured. The binder content was determined according to ASTM C1437-15 (Standard Test Method for Flow Cement Mortar). Figure 1 shows the changes in mortar flow for different amounts of binder and the changes in viscosity for MMA contents simultaneously. Based on these test results, the polymeric binder formulations and the mixture proportions of the polymer concrete were determined, as shown in Table 8 .

\subsection{Strength Test}

The compressive strength test was conducted according to ASTM C 579 (Standard test Method for the Compressive Strength of Chemical-Resistant Mortars, Grouts, Monolithic Surfacings, and Polymer Concretes), and the flexural strength test was conducted pursuant to ASTM C 293 (Standard Test Method for the Flexural Strength of Concrete). In this study, $\varnothing 5 \times 10 \mathrm{~cm}$ cylindrical specimens were used for the compressive strength test, and $4 \times 4 \times 16 \mathrm{~cm}$ prism specimens were used for the flexural strength test. The strength test was conducted using a $20-\mathrm{t}$ universal testing machine (Instron 8502).

\subsection{Coefficient of the Thermal Expansion Test}

The coefficient of the thermal expansion test was conducted referring to RILEM TC 113-CPT (PC-13 Method to Test for the Coefficient of Thermal Expansion of Polymer Concrete and Mortar). Each specimen was $100 \times 100 \times 400 \mathrm{~mm}$, and three parallel specimens were made under identical conditions for each batch and were cured for 7 days at the room temperature $\left(20 \pm 5^{\circ} \mathrm{C}\right)$. The thermal expansion test setup is shown in Fig. 2. The TC 113CPT proposes the following formula for the thermal expansion rate.

$$
L=(l-l o) / l o
$$

where $L$ is the thermal expansion rate, $l o$ is the length before heating, and $l$ is the length measured at each temperature.

Furthermore, the TC 133-CPT proposed the following formula for calculating the coefficient of thermal expansion.

$$
\alpha=\Delta \varepsilon / \Delta t
$$

where $\alpha$ is the coefficient of thermal expansion, $\Delta \varepsilon$ is the thermal expansion rate according to the temperature difference, and $\Delta t$ is the temperature difference.

\subsection{Modulus of Elasticity Test}

The modulus of elasticity test was conducted as per ASTM C 469M (Standard Test Method for the Static Modulus of Elasticity and Poisson's Ratio of Concrete in Compression), and the strain was measured with a Data Logger (Tokyo Sokki, TDS-602) by attaching a wire strain gauge $(30 \mathrm{~mm})$. The compressive strength test was executed with $\varnothing 5 \times 10 \mathrm{~cm}$ cylindrical specimens to determine the modulus of elasticity, as shown in Fig. 3.

The modulus of elasticity was calculated as follows:

$$
E=\left(S_{2}-S_{1}\right) /\left(\varepsilon_{2}-0.00005\right)
$$

where $E$ is the modulus of elasticity $(\mathrm{MPa}), S_{1}$ is the stress for longitudinal strain of $0.00005(\mathrm{MPa}), S_{2}$ is the stress 


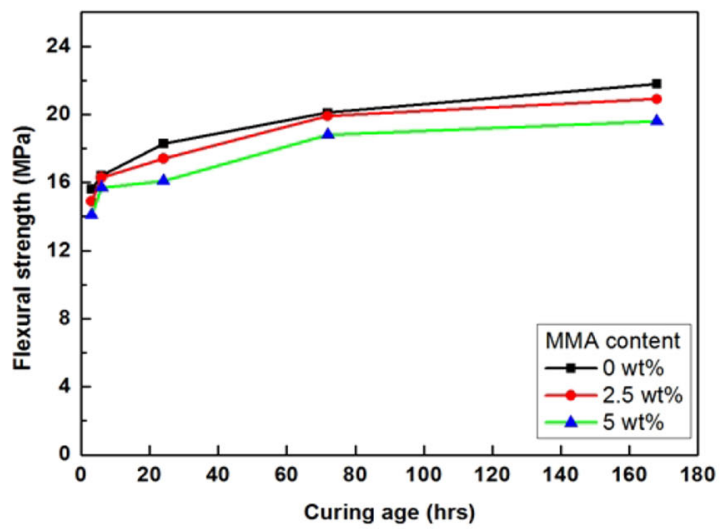

(a)

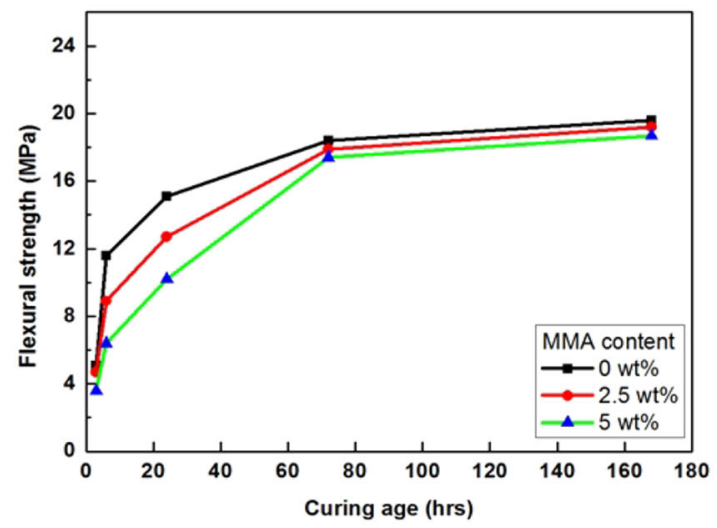

(c)

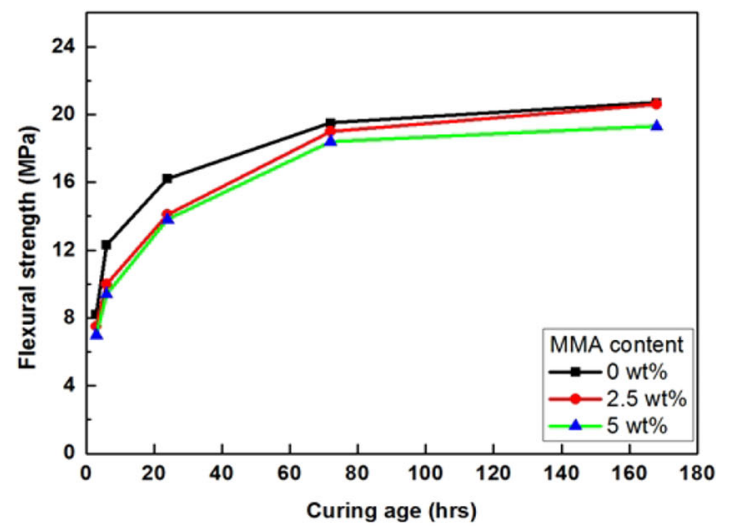

(b)

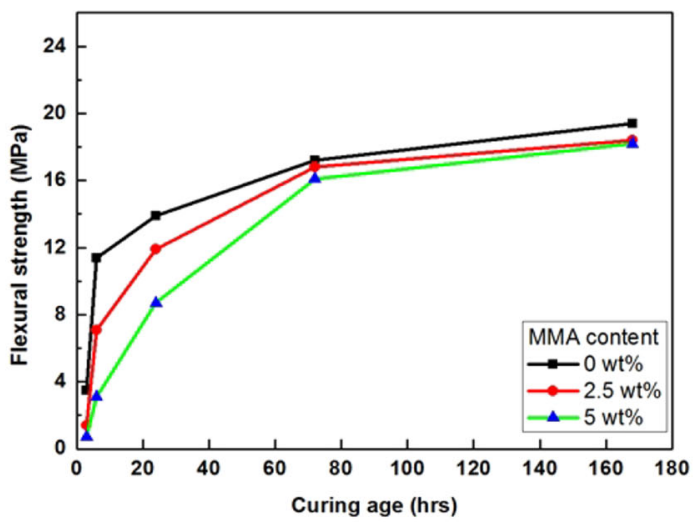

(d)

Fig. 8 Curing age versus flexural strength with MMA content. a $20^{\circ} \mathrm{C}, \mathbf{b} 10^{\circ} \mathrm{C}, \mathbf{c} 0{ }^{\circ} \mathrm{C}$, and d $-10^{\circ} \mathrm{C}$.

corresponding to $40 \%$ of ultimate stress $(\mathrm{MPa})$, and $\varepsilon_{2}$ is the longitudinal strain caused by the stress.

\section{Results and Discussion}

\subsection{Compressive Strength}

The compressive strength developments according to MMA contents and curing temperatures are shown in Figs. 4 and 5 , respectively. As seen in the results, the compressive strength tended to rapidly increase until $24 \mathrm{~h}$ but increased slowly thereafter until $168 \mathrm{~h}$. This tendency varied depending on MMA contents and curing temperatures, with 168-h compressive strength of 43.8-77.2 $\mathrm{MPa}$. These compressive strength values are lower than those of other types of polymer concrete (Haddad et al. 1983; Hyun and Yeon 2012; Son and Yeon 2012).

As shown in Fig. 4, the compressive strengths tended to decrease as MMA contents increased from 0-2.5 and $5 \mathrm{wt} \%$. As a result, the range of the decreased compressive strength at the age of $168 \mathrm{~h}$ was $2.4-6.2 \mathrm{MPa}$. This compressive strength decreased with an increase of an MMA content appears to be due to the phase separation phenomenon (the repulsive force occurring between the interfaces of different materials and preventing complete synthesis) (Hyun and Yeon 2012).

In previous studies, Hyun and Yeon (2012) stated that in UP-MMA polymer concrete, an increase in an UP-MMA ratio (ratio of UP to MMA) to $8: 2,7: 3$, and $6: 4$ led to a decrease in the compressive strength. Patel et al. (1990) stated that an increase in the styrene monomer content of vinyl ester resin resulted in larger strength reductions, similar to the results of this study.

Figure 5 shows the compressive strength changes according to the curing temperatures $(20,10,0$, and $-10{ }^{\circ} \mathrm{C}$ ). According to Fig. 5, lower curing temperature led to a notable decrease in the compressive strength. The extent of the compressive strength reduction according to the curing temperature was greatest at $3 \mathrm{~h}$, and gradually decreased over time. The notable characteristics of the compressive strength development were that a lower curing temperature led to a sharp increase in compressive strength at an early age whereas it led to a lower compressive strength at $3 \mathrm{~h}$.

At $168 \mathrm{~h}$, the compressive strengths (at curing temperature of 20 and $-10{ }^{\circ} \mathrm{C}$ ) were 77.2 and 49.7, 76.0 and 48.8, and 74.8 and $43.8 \mathrm{MPa}$ with MMA contents of $0,2.5$, and $5 \mathrm{wt} \%$, respectively, indicating a $28.5 \mathrm{MPa}$ reduction on average. These results show that the curing temperature had a significant effect on the strength development of MMAmodified vinyl ester polymer concrete. In particular, at the age of $168 \mathrm{~h}$, the measured compressive strength was lowest at $43.8 \mathrm{MPa}$ with an MMA content of $5 \mathrm{wt} \%$ and a curing temperature of $-10{ }^{\circ} \mathrm{C}$, which was much higher than the 28-day compressive strength for portland cement concrete (4.8 $\mathrm{MPa})$ and high-performance concrete $(30.6 \mathrm{MPa})$ at $-5{ }^{\circ} \mathrm{C}$ curing temperature (Cook et al. 1997). This study 


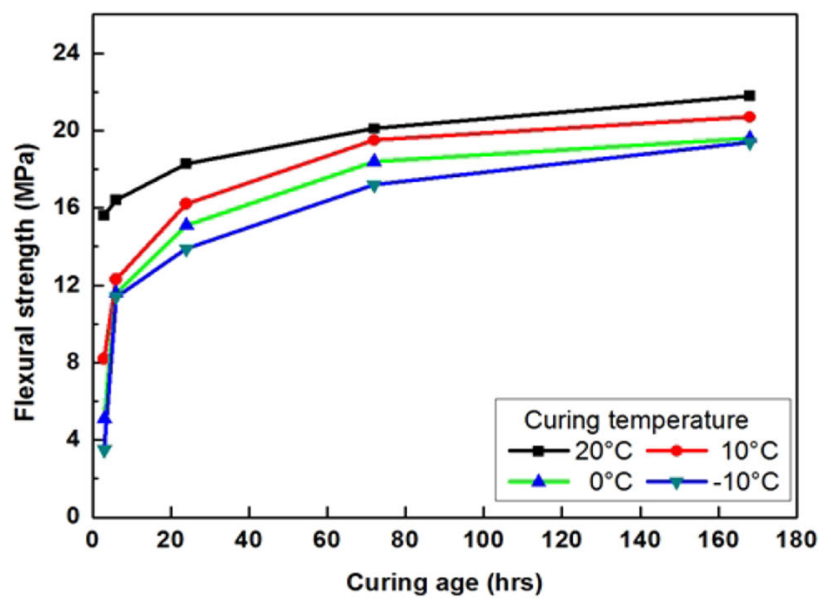

(a)

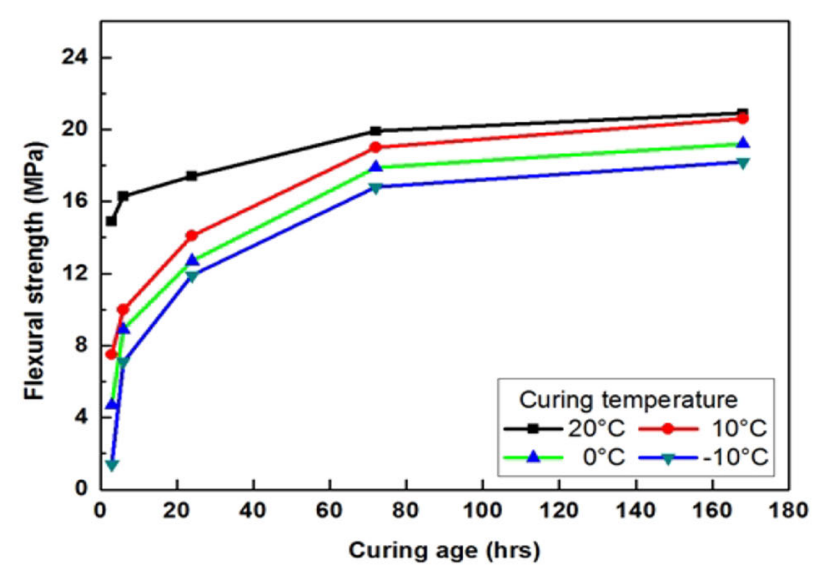

(b)

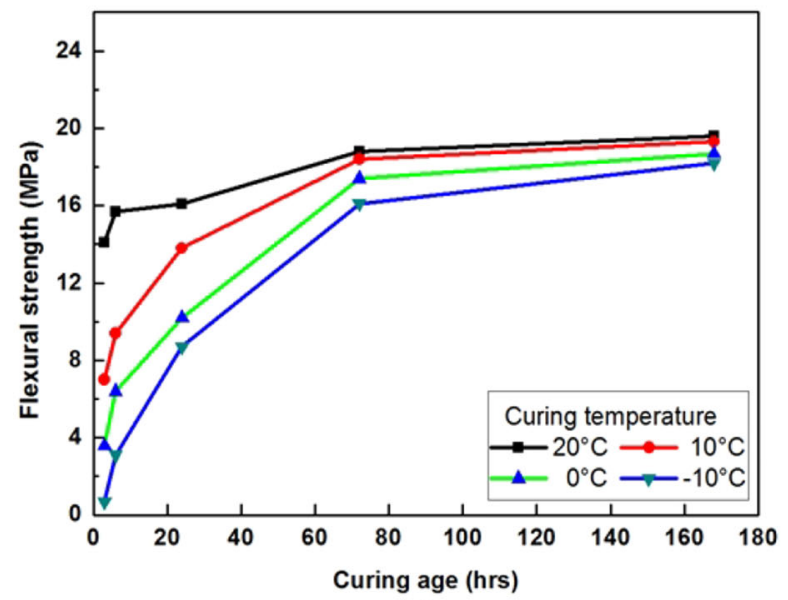

(c)

Fig. 9 Curing age versus flexural strength with curing temperature. a MMA $0 \mathrm{wt} \%$, b MMA $2.5 \mathrm{wt} \%$, and c MMA 5 wt $\%$.

result shows that MMA-modified vinyl ester polymer concrete develops the high strength (even at a low temperature).

To obtain more detailed information on the effects of MMA contents on the compressive strength, Fig. 6 shows that each relative gain of compressive strength was determined after comparing with $0 \mathrm{wt} \% \mathrm{MMA}$ content as criteria of an MMA content. Also, Fig. 7 shows that each relative gain of compressive strength was determined after comparing with $20^{\circ} \mathrm{C}$ curing temperature as criteria to investigate

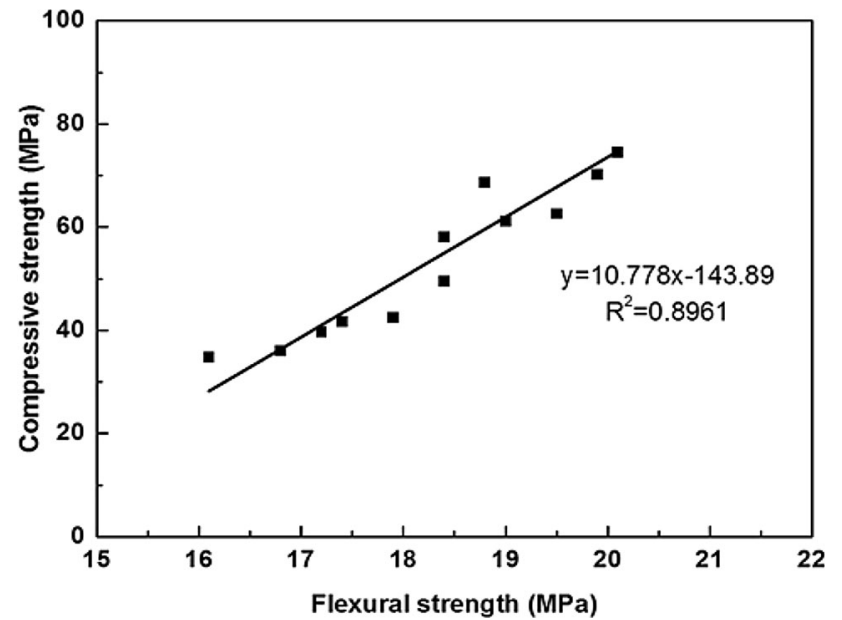

Fig. 10 Relationship between compressive strength and flexural strength.

more specific information on the compressive strength relating the effects of curing temperatures. Figure 6 shows that the relative gains of the compressive strengths were compared with criteria of an MMA content $(0 \mathrm{wt} \% \mathrm{MMA}$ content) from the age of $3 \mathrm{~h}$ to the age of $168 \mathrm{~h}$. The results show that the relative gains of the compressive strengths regarding $5 \mathrm{wt} \%$ MMA content were from 74.8 to $93.5 \%$. Meanwhile, the relative gains of the compressive strengths regarding $2.5 \mathrm{wt} \%$ MMA content were from 91.4 to $97.4 \%$. These results show a lower relative gain with an increase in MMA contents.

In addition, Fig. 7 shows that the relative gains of the compressive strengths were compared with criteria of a curing temperature $\left(20^{\circ} \mathrm{C}\right)$ from the age of $3 \mathrm{~h}$ to the age of $168 \mathrm{~h}$. The results show that the relative gains of the compressive strengths regarding $10{ }^{\circ} \mathrm{C}$ curing temperature were from 40.6 to $86.4 \%$. Plus, the relative gains of the compressive strengths regarding $0{ }^{\circ} \mathrm{C}$ curing temperature were from 10.6 to $75.3 \%$. Moreover, the relative gains of the compressive strengths for $-10{ }^{\circ} \mathrm{C}$ curing temperature were from 5.8 to $62.5 \%$. Thus, these results show a notably lower relative gain with a decrease in curing temperatures.

Thus, compared to ordinary portland cement concrete (with a water/cement ratio of 0.6 ), whose compressive strength development was 11, 41, and $68 \%$ at 1, 3, and 7 days, respectively (Neville 1997), polymer concrete had the high compressive strength even at a very early age.

According to the previously mentioned results, the relative gains of compressive strengths of MMA-modified vinyl ester polymer concrete decreased with an increase of MMA contents and a decrease in curing temperatures, and curing temperatures had a more sensitive effect than MMA contents on strength developments.

\subsection{Flexural Strength}

The results by ages of the flexural strength test according to MMA contents and curing temperatures are shown in Figs. 8 and 9, respectively. In these figures, the development of the flexural strength tends to rapidly increase until the age 


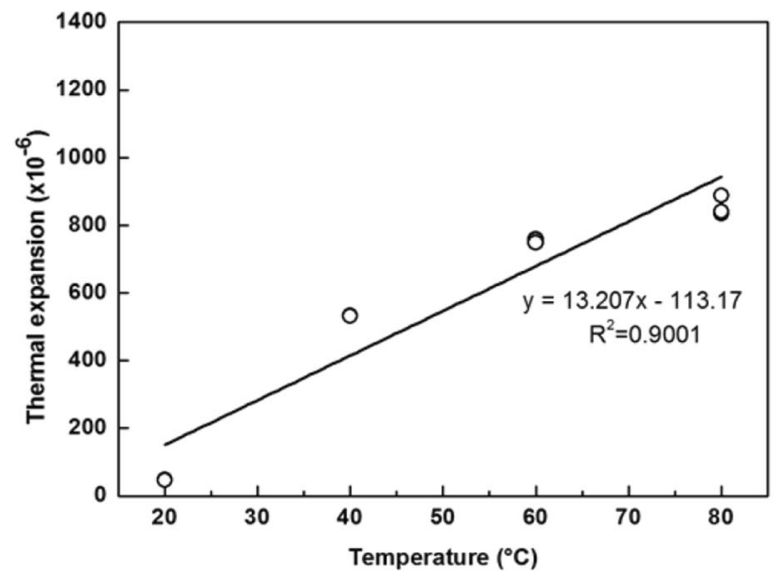

(a)

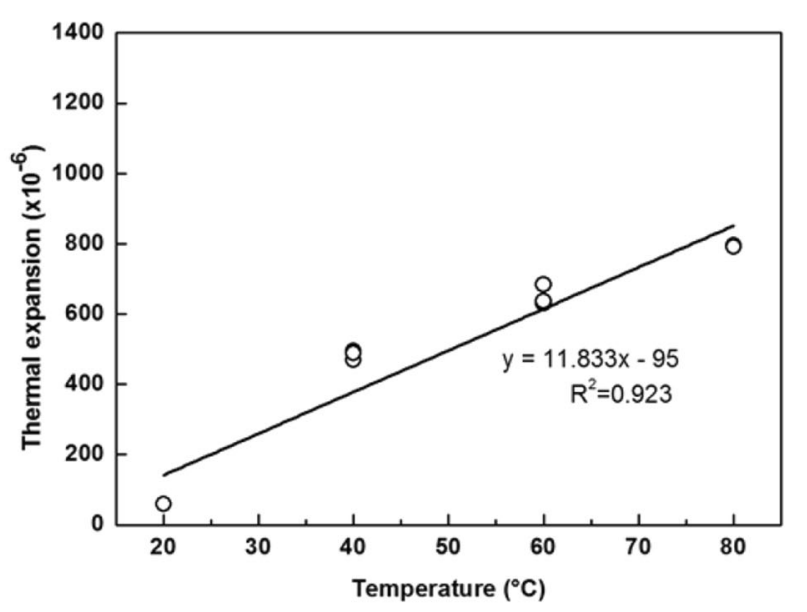

(b)

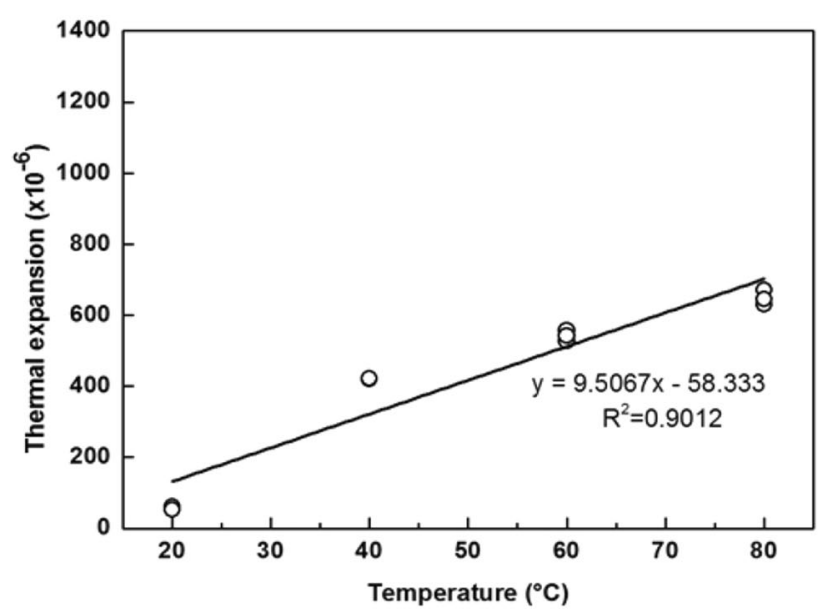

(c)

Fig. 11 Relationship between temperature and thermal expansion. a MMA 0 wt $\%$, b MMA 2.5 wt $\%$, and c MMA $5 \mathrm{wt} \%$.

of $24 \mathrm{~h}$. But it slowly increases until the age of $168 \mathrm{~h}$. The 168-h flexural strength was affected by both MMA contents and curing temperatures. According to MMA contents, the changes of the flexural strength developments are shown in Fig. 8. The development of the flexural strength decreased when an MMA content was increased to from 2.5 to $5 \mathrm{wt} \%$, compared to an MMA content of $0 \mathrm{wt} \%$. As a result, the magnitude of the decreased flexural strength was from 0.9 to
2.2 $\mathrm{MPa}$ at the age of $168 \mathrm{~h}$. According to the flexural strength test results regarding the curing temperatures $(20,10,0$, and $-10{ }^{\circ} \mathrm{C}$ ) applied in this study, the flexural strengths were notably decreased as the curing temperature is decreased as shown in Fig. 9. According to the curing temperature, the decreased magnitude of the flexural strength was greatest at the age of $3 \mathrm{~h}$ and gradually became weaker over time. At $168 \mathrm{~h}$, the developed flexural strengths at curing temperatures of 20 and $-10{ }^{\circ} \mathrm{C}$ were 21.8 and $19.4 \mathrm{MPa}$ for $0 \mathrm{wt} \% \mathrm{MMA}$, 20.9 and 18.4 MPa for 2.5 wt\% MMA, 19.6 and 18.2 MPa for $5 \mathrm{wt} \%$ MMA, respectively. Based on these investigations, the identified reduction of the flexural strength was $2.1 \mathrm{MPa}$ on average. According to these results, it was determined that the effects of MMA contents and curing temperatures on the flexural strength developments are very similar to the results regarding the effects of MMA contents and curing temperatures on the compressive strength results.

The data obtained by compressive and flexural strength tests were applied to a regression analysis to define their relations and the results of a regression analysis are shown in Fig. 10. The compressive strength-flexural strength regression equation, obtained by analyzing the data, was $y=10.778 x-143.89$ with a coefficient of determination $R^{2}$ of 0.8961 . Thus, once either the compressive strength or the flexural strength is determined, this equation can be applied to estimate a corresponding value of the compressive strength or a corresponding value of the flexural strength.

\subsection{Coefficient of Thermal Expansion}

The thermal expansion rates of vinyl ester polymer concrete according to MMA contents are shown in Fig. 11. Also, the coefficients of thermal expansion calculated based on Fig. 11 is shown in Table 9. In Fig. 11, the maximum thermal expansion rates were $890 \times 10^{-6}, 821 \times 10^{-6}$, and $672 \times 10^{-6}$ at MMA contents of $0,2.5$, and $5 \mathrm{wt} \%$, respectively. The relation between the test temperature and the coefficient of thermal expansion can be defined as a linear regression equation, and the coefficient of determination $R^{2}$ was 0.9 or higher, showing a high correlation. As shown in Table 9, the coefficients of thermal expansion were $14.23 \times 10^{-6}, 13.25 \times 10^{-6}$, and $10.82 \times 10^{-6} /{ }^{\circ} \mathrm{C}$ for MMA contents of $0,2.5$, and $5 \mathrm{wt} \%$, respectively, thus showing a decreasing trend as MMA contents increased. This shows that adding MMA is effective in reducing the coefficient of thermal expansion. The coefficients of thermal expansion were measured under the temperature range from 20 to $80{ }^{\circ} \mathrm{C}$ for this study. But the coefficients of thermal expansion could be increased if more practical temperature range from 20 to $60{ }^{\circ} \mathrm{C}$ was applied.

The thermal expansion coefficient test results from this study were lower than those of previous studies (UP-MMA polymer concrete's coefficient of thermal expansion was $21.6 \times 10^{-6}$ to $31.2 \times 10^{-6} /{ }^{\circ} \mathrm{C}$, epoxy polymer mortar was $28.60 \times 10^{-6} /{ }^{\circ} \mathrm{C}$, unsaturated polyester polymer mortar was $23.00 \times 10^{-6} /{ }^{\circ} \mathrm{C}$, and PMMA polymer mortar was $\left.21.50 \times 10^{-6} /{ }^{\circ} \mathrm{C}\right)($ Omata et al. 1995; Yeon and Yeon 2012) and were similar to the results for ordinary portland cement concrete $\left(11.1 \times 10^{-6} /{ }^{\circ} \mathrm{C}\right)($ Omata et al. 1995). 
Table 9 Test results of the thermal expansion coefficient.

\begin{tabular}{|c|c|c|c|c|}
\hline MMA content (wt $\%)$ & Specimen & $\begin{array}{l}\text { Coefficient of thermal } \\
\text { expansion }\left(\times 10^{-6} /{ }^{\circ} \mathrm{C}\right)\end{array}$ & Mean $\left(\times 10^{-6} /{ }^{\circ} \mathrm{C}\right)$ & SD \\
\hline \multirow[t]{3}{*}{0} & A & 13.90 & \multirow[t]{3}{*}{14.23} & \multirow[t]{3}{*}{ \pm 0.40} \\
\hline & B & 14.80 & & \\
\hline & $\mathrm{C}$ & 14.00 & & \\
\hline \multirow[t]{3}{*}{2.5} & A & 13.20 & \multirow[t]{3}{*}{13.25} & \multirow[t]{3}{*}{ \pm 0.04} \\
\hline & B & 13.25 & & \\
\hline & $\mathrm{C}$ & 13.20 & & \\
\hline \multirow[t]{3}{*}{5} & A & 10.50 & \multirow[t]{3}{*}{10.82} & \multirow[t]{3}{*}{ \pm 0.29} \\
\hline & B & 11.20 & & \\
\hline & $\mathrm{C}$ & 10.75 & & \\
\hline
\end{tabular}

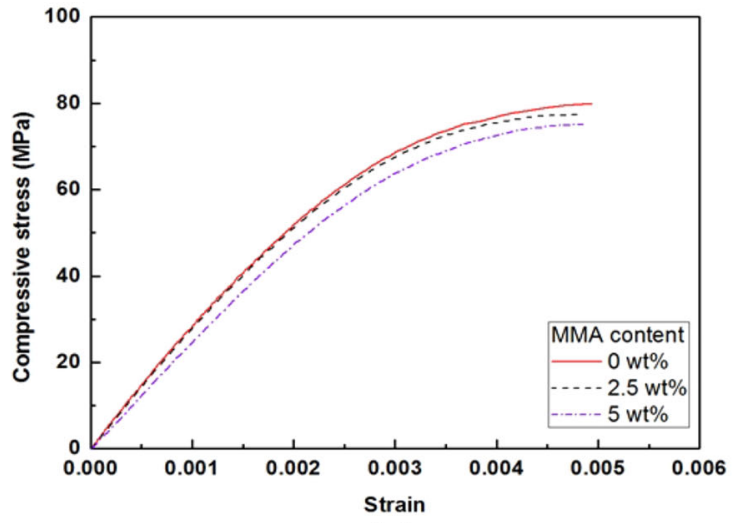

(a)

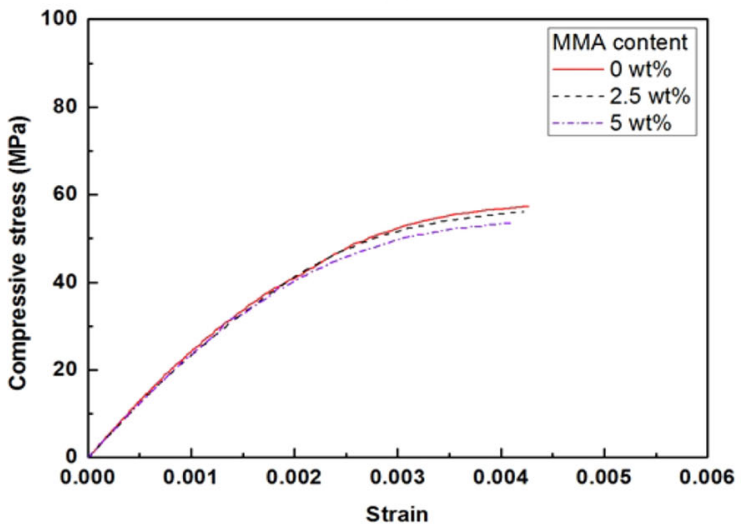

(c)

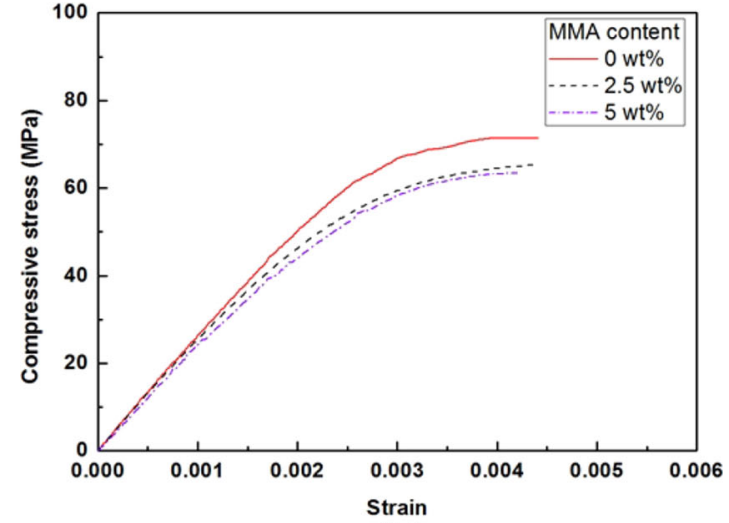

(b)



(d)

Fig. 12 Compressive stress-strain curves. a $20^{\circ} \mathrm{C}$, b $10^{\circ} \mathrm{C}, \mathbf{c} 0^{\circ} \mathrm{C}$, and d $-10^{\circ} \mathrm{C}$.

Table 10 Test results of the elastic modulus (unit: $\times 10^{4} \mathrm{MPa}$ ).

\begin{tabular}{c|c|c|c}
\hline Curing temperature $\left({ }^{\circ} \mathrm{C}\right)$ & MMA 0 wt $\%$ & MMA 2.5 wt $\%$ & MMA 5 wt $\%$ \\
\hline \hline 10 & 2.51 & 2.38 & 2.24 \\
\hline 0 & 2.53 & 2.46 & 2.41 \\
\hline 10 & 2.63 & 2.57 & 2.43 \\
\hline 20 & 2.90 & 2.83 & 2.48 \\
\hline
\end{tabular}




\subsection{Modulus of Elasticity}

The static modulus of elasticity for a material under tension or compression is given by the slope of the stress-strain curve for concrete under uniaxial loading. Since the stressstrain curve for portland cement concrete is nonlinear, three types of elastic modulus existed: tangent modulus, secant modulus, and chord modulus. In this study, compressive loading was applied, and the secant modulus, among those three types, was defined. The secant modulus is given by the slope of a line drawn from the origin to a point on the curve corresponding to a $40 \%$ stress of the failure load (Mehta and Monteiro 2006).

The effects of curing temperatures on the compressive stress-strain curves according to MMA contents are shown in Fig. 12. Also, the modulus of elasticity was calculated, and the results are shown in Table 10. The ultimate strains, being 0.00406-0.00494, 0.00401-0.00481, and $0.00391-0.00485$ at MMA contents of $0,2.5$, and $5 \mathrm{wt} \%$, respectively, tended to decrease with an increase in MMA contents and to notably decrease with a decrease in curing temperatures. These determined ultimate strains in this study are similar to UP-MMA polymer concrete's ultimate strains (0.00381-0.00418) (Yeon and Yeon 2012). However, those values are lower than the ultimate strains of PMMA polymer concrete (0.0046-0.0061) (Son and Yeon 2012).

Lastly, Table 10 shows that the modulus of elasticity ranged from $2.24 \times 10^{4}$ to $2.90 \times 10^{4} \mathrm{MPa}$. The elastic modulus values tended to decrease as MMA contents increased and curing temperatures decreased. These elastic modulus values are lower than that of portland cement concrete $\left(3.6 \times 10^{4} \mathrm{MPa}\right)$ when the development of a compressive strength is $60 \mathrm{MPa}$ (Neville 1997) and that of UP-MMA polymer concrete $\left(2.8 \times 10^{4}\right.$ to $\left.3.3 \times 10^{4} \mathrm{MPa}\right)$ (Yeon and Yeon 2012).

\section{Conclusions}

This study investigated the strength developments and deformation characteristics of MMA-modified vinyl ester polymer concrete with different MMA contents $(0,2.5$, and $5 \mathrm{wt} \%)$ and curing temperatures $\left(-10,0,10\right.$, and $\left.20^{\circ} \mathrm{C}\right)$. The results of this study can be summarized as follows:

(1) According to the results of compressive strength tests, the range of the compressive strength was between 43.8 and $77.2 \mathrm{MPa}$ at the age of $168 \mathrm{~h}$. The identified range of the compressive strength of MMA-modified vinyl ester polymer concrete was lower than the compressive strength range of other types of polymer concrete. Also, the compressive strength tended to decrease with an increase in MMA contents and a decrease in curing temperatures.

(2) The flexural strength test results showed that the range of flexural strength was between 18.2 and $21.8 \mathrm{MPa}$ at the age of $168 \mathrm{~h}$. The flexural strengths also decreased when MMA contents were increased and the curing temperatures were decreased.
(3) The coefficients of thermal expansion were $14.23 \times 10^{-6}, 13.25 \times 10^{-6}$, and $10.82 \times 10^{-6} /{ }^{\circ} \mathrm{C}$ for $0,2.5$, and $5 \mathrm{wt} \%$ MMA contents, respectively, showing a decrease with an increase in MMA contents.

(4) According to the results of strain measurements, the ultimate strain varied between 0.00391 and 0.00494 . The measured strains tended to decrease with an increase in MMA contents and to notably decrease with a decrease in curing temperatures. The values were similar to or slightly lower than those of other types of polymer concrete.

(5) The range of the elastic modulus was between $2.24 \times 10^{4}$ and $2.90 \times 10^{4} \mathrm{MPa}$. It was found that the modulus of elasticity decreased with an increase in MMA contents and a decrease in curing temperatures. The values were lower than those of ordinary portland cement concrete or other types of polymer concrete.

\section{Open Access}

This article is distributed under the terms of the Creative Commons Attribution 4.0 International License (http:// creativecommons.org/licenses/by/4.0/), which permits unre stricted use, distribution, and reproduction in any medium, provided you give appropriate credit to the original author(s) and the source, provide a link to the Creative Commons license, and indicate if changes were made.

\section{References}

Cao, X., \& Lee, L. J. (2003). Control of shrinkage, and final conversion of vinyl ester resins cured in low-temperature molding processes. Journal of Applied Polymer Science, 90, 1486-1496. https://doi.org/10.1002/app.12649.

Chandra, S., \& Ohama, Y. (1994). Polymers in concrete. Boca Raton: CRC Press Inc.

Choi, K. B., Min, S. H., \& Yeon, K. S. (2016). Setting shrinkage characteristics of methyl methacrylate-modified vinyl ester polymer concrete. American Journal of Applied Sciences, 14(2), 586-592. https://doi.org/10.3844/ajassp.2016.586. 592.

Cook, W. D., Simon, G. P., Burchill, P. J., Lau, M., \& Fitch, T. J. (1997). Curing kinetics and thermal properties of vinyl ester resins. Journal of Applied Polymer Science, 64(4), 769-781. https://doi.org/10.1002/(SICI)10974628(19970425)64:4<769:AID-APP16>3.0.CO;2-P.

Fowler, D. W. (1989). Future trends in polymer concrete. In: Polymers in concrete: Advances and applications, ACI SP116, pp. 129-143.

Haddad, M. U., Fowler, D. W., \& Paul, D. R. (1983). Factors affecting the curing and strength of polymer concrete. Journal of the American Concrete Institute, 80(5), 396-402. https://doi.org/10.14359/10863.

Hyun, S. H., \& Yeon, J. H. (2012). Strength development characteristics of UP-MMA based polymer concrete with 
different curing temperature. Construction and Building Materials, 37, 387-397. https://doi.org/10.1016/j.con buildmat.2012.07.094.

Martin, J. S., Laza, J. M., Morras, M. L., Rodriguez, M., \& Leon, L. M. (2000). Study of the curing process of a vinyl ester resin by means of TRS and DMTA. Polymer, 41, 4203-4211. https://doi.org/10.1016/S0032-3861(99)00631$\mathrm{X}$.

Mehta, P. K., \& Monteiro, P. J. M. (2006). Concrete-microstructure, properties, and materials (3rd ed.). New York: McGraw-Hill.

Neville, A. M. (1997). Properties of concrete (4th ed.). Hoboken: Wiley.

Ohama, Y. (1973). Mix proportions and properties of polyester resin concretes. In: Polymers in concrete, ACI SP-40, pp. 283-294.

Omata, F., Kawakami, M., Wakayama, S., \& Yamamura, H. (1995). Thermal stress and setting shrinkage stress of concrete members repaired by polymer mortar. In: Proceedings of the 8th International Congress on Polymers in Concrete, Oostende, Belgium, pp. 113-118.

Patel, R. D., Thakkar, J. R., Patel, R. G., \& Patel, V. S. (1990). Glass-reinforced vinyl ester resin composites. High Performance Polymers, 2, 261-265. https://doi.org/10.1177/ 095400839000200406.

Son, S. W., \& Yeon, J. H. (2012). Mechanical properties of acrylic polymer concrete containing methacrylic acid as an additive. Construction and Building Materials, 37, 669-679. https:// doi.org/10.1016/j.conbuildmat.2012.07.093.

Yeon, K. S., \& Yeon, J. H. (2012). Setting shrinkage, coefficient of thermal expansion, and elastic modulus of UP-MMA based polymer concrete. Journal of the Korea Concrete Institute, 24(4), 491-498. https://doi.org/10.4334/JKCI. 2012.24.4.491. 